\title{
Thoracic Spinal Stenosis: Surgical Approaches and Outcomes
}

\author{
Aykut Gokbel $^{1(\mathbb{D})}$, Mehmet Secer ${ }^{2(\mathbb{D})}$, Tugba Gokbel ${ }^{3(\mathbb{D})}$ \\ ${ }^{1}$ Department of Neurosurgery, Kocaeli Derince Education and Research Hospital, Kocaeli, Turkey \\ ${ }^{2}$ Department of Neurosurgery Faculty of Medicine, Alaaddin Keykubat University, Alanya, Turkey \\ ${ }^{3}$ Department of Physical Medicine and Rehabilitation, Kocaeli University Faculty of Medicine, Kocaeli, Turkey
}

Copyright@ Author(s) - Available online at https://dergipark.org.tr/en/pub/mbsjohs Content of this journal is licensed under a Creative Commons Attribution-NonCommercial 4.0 International License,

Received: 23 June 2021, Accepted: 12 August 2021, Published online: 31 August 2021

(C) Ordu University Institute of Health Sciences, Turkey, 2021

\begin{abstract}
Objective: Thoracic spinal stenosis (TSS) develops as a result of decreased spinal canal volume in the thoracic spine. The prevalence of TSS is low as when compared with cervical or lumbar spinal stenosis, and conservative treatment is not effective. The present study aimed to present all surgical methods employed and their outcomes in patients diagnosed with TSS in our clinic.

Methods: In this study, the data of 14 patients including three patients with single-level, nine patients with two-level, one patient with three-level, and one patient with multilevel TSS and hypophosphatemic rickets who underwent surgery due to TSS, were retrospectively evaluated using the discharge summary, surgical reports, and preoperative and postoperative radiological images.

Results: The age of the patients ranged from 53 to 68 years. Of the patients included in the study, one underwent hemilaminectomy, two underwent total laminectomy, six underwent laminoplasty, and five underwent total laminectomy with fusion and posterior instrumentation. A dramatic improvement was observed in the neurological deficits existing in the preoperative period in patients who were diagnosed in the early period and underwent surgery with adequate decompression before the development of severe neurological deficits and who continued postoperative rehabilitation added to the treatment.

Conclusion: Patients with TSS have an insidious clinical course manifested by upper motor neuron symptoms. Although the prevalence of TSS is low, early diagnosis and treatment are important. The results of surgery are satisfactory when adequate decompression is achieved before the clinical condition worsens. Key words: Spinal stenosis, ossification, dura mater, ligamentum flavum
\end{abstract}

Suggested Citation: Gokbel A, Secer M, Gokbel T. Thoracic Spinal Stenosis: Surgical Approaches and Outcomes.Mid Blac Sea Journal of Health Sci, 2021; 7(2):212-220

\section{Address for correspondence/reprints:}

Aykut Gokbel

Telephone number: 905079272613

E-mail: aykutgokbelnrs@gmail.com 


\section{Introduction}

Thoracic spinal stenosis (TSS) is a clinical condition in which neurological dysfunction characterized by a reduction in the volume of the thoracic spinal canal occurs, leading to compromise of the spinal cord and/or nerve roots (1). According to the location of TSS, it can be divided into two as ventral and dorsal stenosis. Ventral stenosis is caused by broad-based thoracic intervertebral disc protrusion and ossification of the posterior longitudinal ligament. Dorsal stenosis is caused by the ossification of the ligamentum flavum (OLF) or facets joint hypertrophy (2). The most common cause of TSS, especially in East Asian countries, is the OLF (3). The OLF usually occurs at the lower thoracic spine, especially at the T10-T12 levels (4-6), followed by the upper thoracic spine at the T1-T4 (7) levels, due to increased biomechanical stress. The prevalence of TSS is lower than that of cervical or lumbar spinal stenosis (8); moreover, if neurological symptoms occur, conservative therapy is not effective and early decompressive surgery is required $(2,8,9)$. Since neurological symptoms mostly affect the lower extremities, TSS can be confused with lumbar spinal pathologies and patients may be clinically misdiagnosed $(2,10)$. Generally, patients present to the clinic with symptoms of progressive thoracic myelopathy, back pain, and/or signs of acute severe paraparesis or paraplegia after minor trauma $(4-6,11)$.

The present study aims to present all surgical methods employed and their outcomes in patients diagnosed with TSS in our clinic.

\section{Methods}

In this study, the data of 14 patients who were operated with the diagnosis of TSS were retrospectively evaluated using the discharge summary, surgical reports, and preoperative and postoperative radiological images. The study was approved by the ethics committee of Kocaeli Derince Education and Research Hospital (project number 2020/42).

Of the patients included in the study, one underwent hemilaminectomy, two underwent total laminectomy, six underwent laminoplasty, and five underwent total laminectomy with fusion and posterior instrumentation.

In patients undergoing bilateral decompression with unilateral hemilaminectomy (Figure 1, 2), paravertebral muscles were unilaterally stripped from the spinous processes and vertebral bones through a midline incision. Under the microscope, hemilaminectomy was performed with ultrasonic bone cutter and high-speed drills, while remaining medial to the facet joint. Then, the junction of the lamina and the spinous process was thinned with a drill. The thinned lamina in some areas was removed with the help of a curette and a rongeur. This technique was used in one patient. By performing unilateral muscle dissection in this technique, operation time is shortened, perioperative bleeding is reduced, and spinal instability is avoided by sparing the facet joints. Therefore, the use of a corset in the postoperative period is no longer needed. However, failure to achieve the appropriate angle may cause insufficient contralateral decompression.

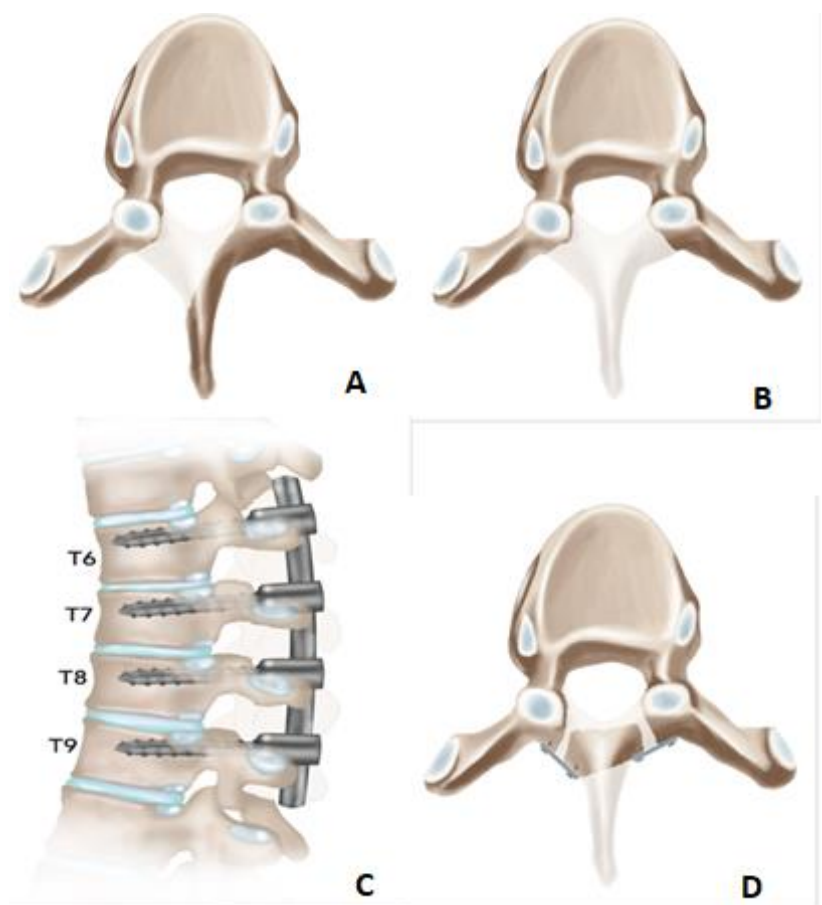

Figure 1. A: Bilateral decompression with unilateral hemilaminectomy, B: Total laminectomy, C: Total laminectomy with fusion and posterior instrumentation, D: Laminoplasty

In patients undergoing total laminectomy (Figure $1,3)$, the paravertebral muscles were stripped from the spinous processes and vertebral bones after performing a midline incision. The dissection was advanced to the medial aspect of the facet joints and care was taken not to damage the facet joint capsule. The lamina and OLF were dissected off the dura using an ultrasonic bone cutter and a high-speed drill while preserving the facet joints. This technique was used in two patients. A clearer view of the borders of the central canal and neural foramen was achieved compared to hemilaminectomy. Similar to that in hemilaminectomy, the risk of spinal instability was reduced as the facet joints were preserved. The use of corsets in the postoperative period was not required in both patients. However, the removal of more posterior elements than hemilaminectomy and the 
disruption of the integrity of midline tension band structures caused postoperative pain. Also in this technique, preserving the facet joints to avoid instability may cause inadequate decompression.

In five patients undergoing total laminectomy with fusion and posterior instrumentation Figure 1, 4), the paravertebral muscles were stripped from the spinous processes and vertebral bones through a midline incision. Then, pedicle screws were inserted, and total laminectomy was performed at the levels of stenosis by removing the facet faces using a Kerrison rongeur and rongeur. Since stabilization was achieved using the pedicle screws, the margin of laminectomy was widened to include the facet joints. Extensive decompression was achieved. Since a wide incision is made with this technique and the muscles are retracted, perioperative bleeding and postoperative pain may be more common in patients, and screw malposition may be observed.

In six patients undergoing laminoplasty, the laminoplasty technique that we applied was a modification of the previously described classical laminoplasty technique (Figure 1, 5). Z-laminoplasty, open-door laminoplasty, double-door laminoplasty methods were not used in this technique. In one of the cases in which we applied this technique, there was severe multiple stenosis. Absolute stenosis was detected in the patient at T3, T4, T6, T7, T8, T9, T11, $\mathrm{T} 12$ levels. If laminectomy was performed by fusion with posterior instrumentation, it would have been necessary to apply a very long-segment stabilization from the cervicothoracic junction, including the thoracolumbar junction. Instead, total laminectomy was performed at eight levels of stenosis in this patient using Kerrison rongeur, rongeur, and highspeed drills. Posterior stabilization was achieved by fixing the removed spinous part to the facet joints and transverse processes with a mini-plate screw in a horizontal position. Since long-segment posterior instrumentation was not performed in this patient, the operation time was very short, there was no screw malposition problem, and perioperative bleeding was minimal. However, the use of a corset in the postoperative period was required in this patient as the technique employed may cause stabilization problems.
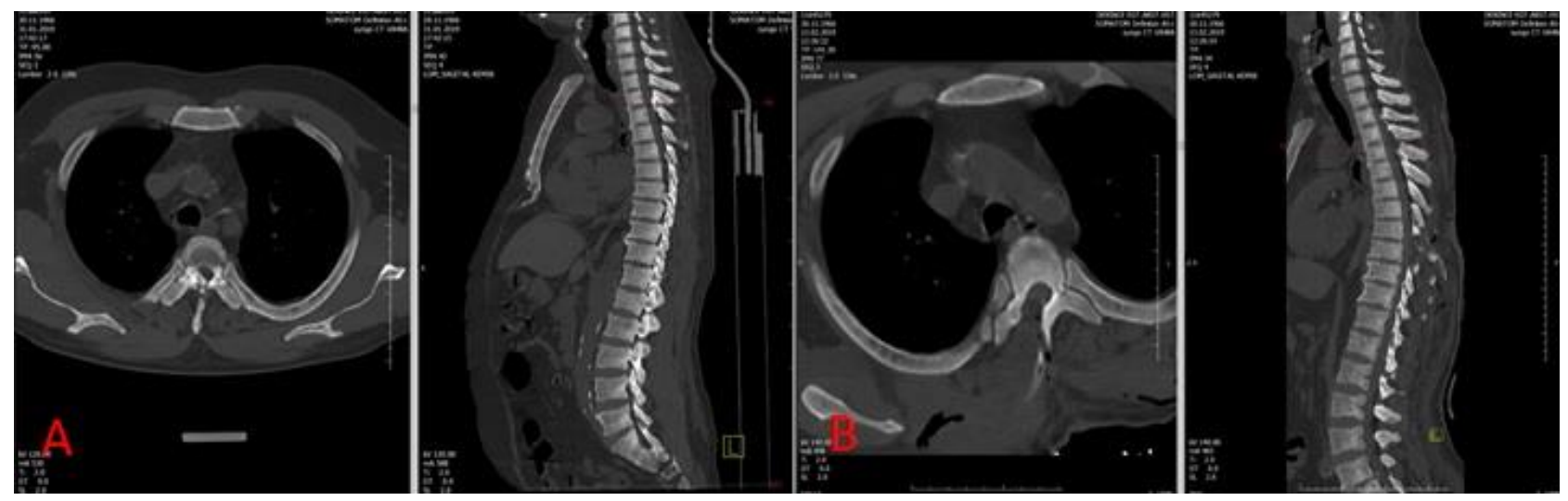

Figure 2. Images of computerized tomography (CT) axial and sagittal sections in a patient who underwent bilateral decompression with unilateral hemilaminectomy (R) A. Preoperative B. Postoperative

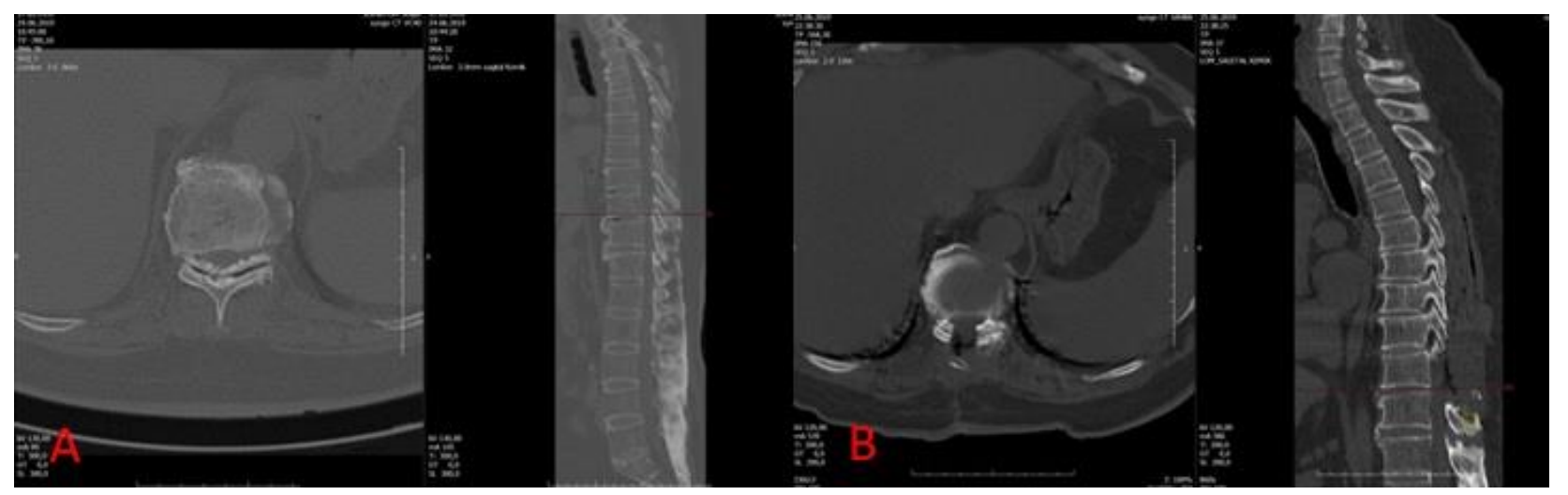

Figure 3. Images of computerized tomography $(\mathrm{CT})$ axial and sagittal sections in a patient who underwent total laminectomy A: Preoperative B: Post-operative 


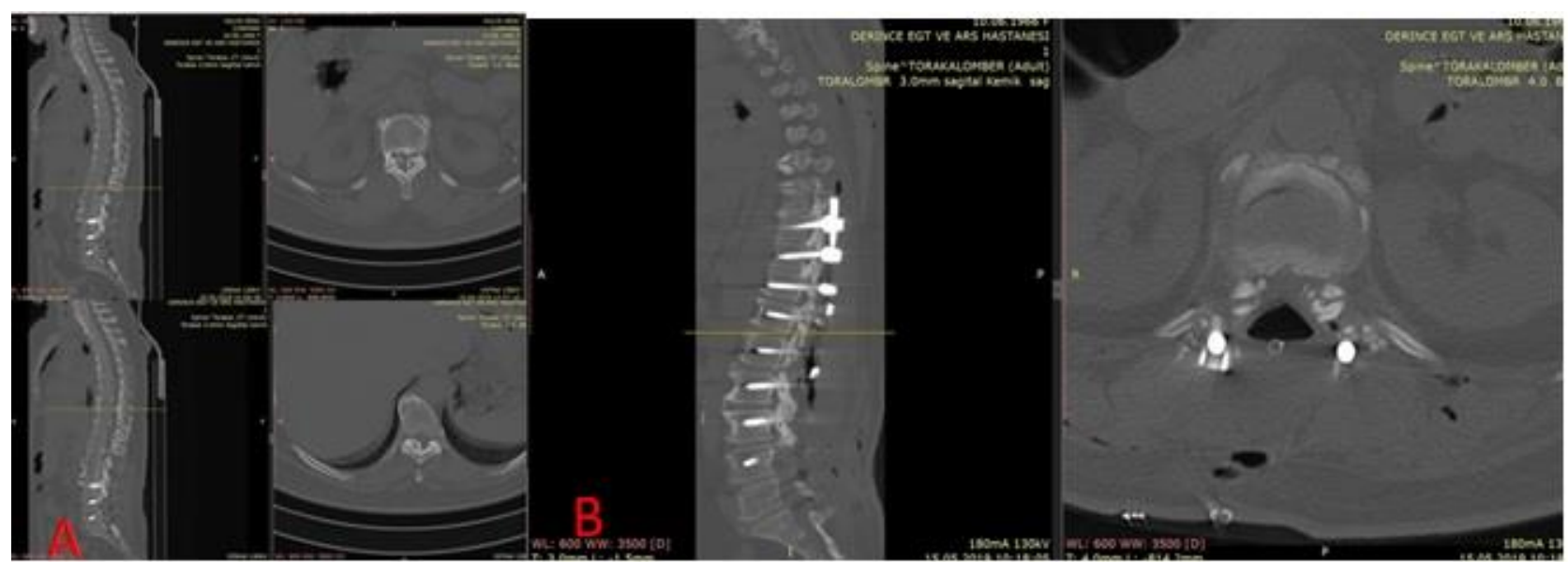

Figure 4. Images of computerized tomography (CT) sagittal and axial sections in a patient who was previously operated on with the diagnosis of lumbar spinal stenosis and underwent total laminectomy with fusion and posterior instrumentation A: Pre-operative B: Post-operative

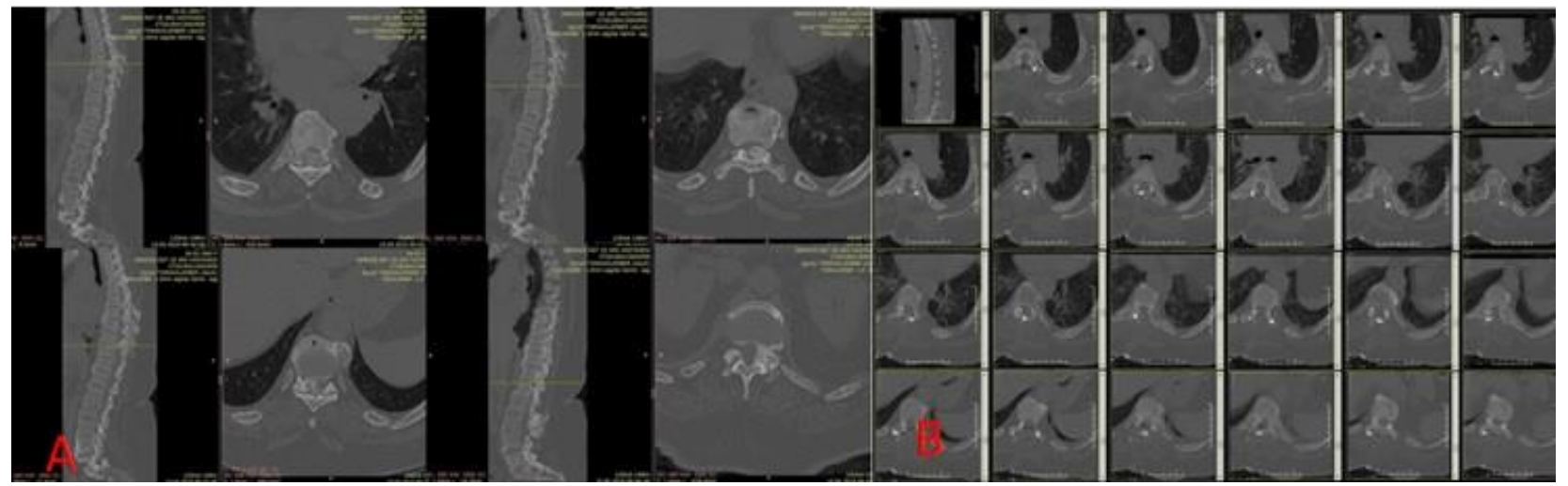

Figure 5. Images of computerized tomography $(\mathrm{CT})$ sagittal and axial sections in a patient with eight levels of thoracic spinal stenosis who underwent laminoplasty A: Pre-operative B: Post-operative

\section{Results}

A total of 14 patients were included in the study, including three patients with single-level, nine patients with two-level, one patient with three-level, and one patient with stenosis at eight levels and with a diagnosis of X-linked hypophosphatemia (XLH). Of the patients, five had type 2 diabetes mellitus and four had chronic renal failure. The age of the patients ranged between 53 and 68 years. Of patients undergoing surgery, two underwent repeat surgery after the observation of inadequate decompression on control computed tomography (CT) examination of the spine in the postoperative period. Two patients developed dural defects due to the presence of severe dural ossification (DO). Dural repair with fascia graft was performed in these cases. In the early postoperative period, the cases were followed up for possible acute complications. Among 14 patients with paraparesis in the preoperative period, complete recovery of paraparesis was observed in seven patients in the postoperative period. The other seven cases were referred to the Physical Medicine and Rehabilitation clinic due to partial persistence of paraparesis. A neurological rehabilitation program, which was planned to include stretching and strengthening exercises, weight-bearing, balance, proprioception, and ambulation training, daily living activities, and splinting program, was applied to these cases. It was observed that there was a dramatic improvement in the existing neurological deficits of the patients with the rehabilitation applications added to the program after surgery. One patient was able to ambulate with a walker and the other six patients were able to ambulate independently without support. During an extended follow-up duration of 1-3 years, the patients did not develop re-stenosis and instability (Table 1). 
Table 1: Presentation of patients

\begin{tabular}{|c|c|c|c|c|c|c|c|c|}
\hline $\begin{array}{l}\text { Patient } \\
\text { number }\end{array}$ & Age & Gender & $\begin{array}{l}\text { Level of } \\
\text { stenosis }\end{array}$ & Pre-op clinic & $\begin{array}{l}\text { Pre-op } \\
\text { calcification }\end{array}$ & Operation & Post-op clinic & $\begin{array}{l}\text { Post-op } \\
\text { complication }\end{array}$ \\
\hline 1 & 58 & Female & $\mathrm{T} 4$ & Paraparesis & OLF & Total laminectomy & $\begin{array}{l}\text { Decrease of } \\
\text { paraparesis }\end{array}$ & - \\
\hline 2 & 57 & Male & T5 & Paraparesis & $\mathrm{OLF}+\mathrm{DO}$ & Total laminectomy & $\begin{array}{l}\text { Decrease of } \\
\text { paraparesis }\end{array}$ & Dura defect \\
\hline 3 & 61 & Male & $\mathrm{T} 4$ & Paraparesis & OLF & $\begin{array}{l}\text { Right } \\
\text { hemilaminectomy }\end{array}$ & $\begin{array}{l}\text { Completely } \\
\text { improvement }\end{array}$ & - \\
\hline 4 & 56 & Female & $\mathrm{T} 10, \mathrm{~T} 11$ & Paraparesis & $\mathrm{OLF}+\mathrm{DO}$ & $\begin{array}{l}\text { Posterior } \\
\text { instrumentation+ } \\
\text { total laminectomy }\end{array}$ & $\begin{array}{l}\text { Completely } \\
\text { improvement }\end{array}$ & - \\
\hline 5 & 54 & Female & T9, T11 & Paraparesis & OLF & $\begin{array}{l}\text { Posterior } \\
\text { instrumentation+ } \\
\text { total laminectomy }\end{array}$ & $\begin{array}{l}\text { Decrease of } \\
\text { paraparesis }\end{array}$ & - \\
\hline 6 & 53 & Male & $\mathrm{T} 10, \mathrm{~T} 12$ & $\begin{array}{l}\text { Pain+ } \\
\text { paraparesis }\end{array}$ & OLF & $\begin{array}{l}\text { Posterior } \\
\text { instrumentation+ } \\
\text { total laminectomy }\end{array}$ & $\begin{array}{l}\text { Completely } \\
\text { improvement }\end{array}$ & - \\
\hline 7 & 54 & Male & $\begin{array}{l}\text { TT9, } \\
\text { T10, T12 }\end{array}$ & $\begin{array}{l}\text { Pain+ } \\
\text { paraparesis }\end{array}$ & $\mathrm{OLF}+\mathrm{DO}$ & $\begin{array}{l}\text { Posterior } \\
\text { instrumentation+ } \\
\text { total laminectomy }\end{array}$ & $\begin{array}{l}\text { Completely } \\
\text { improvement }\end{array}$ & - \\
\hline 8 & 61 & Female & T9, T10 & $\begin{array}{l}\text { Pain+ } \\
\text { paraparesis }\end{array}$ & OLF & Laminoplasty & $\begin{array}{l}\text { Completely } \\
\text { improvement }\end{array}$ & - \\
\hline 9 & 62 & Male & $\mathrm{T} 10, \mathrm{~T} 11$ & Paraparesis & OLF & Laminoplasty & $\begin{array}{l}\text { Decrease of } \\
\text { paraparesis }\end{array}$ & - \\
\hline 10 & 62 & Female & $\mathrm{T} 10, \mathrm{~T} 12$ & $\begin{array}{l}\text { Pain+ } \\
\text { paraparesis }\end{array}$ & OLF & Laminoplasty & $\begin{array}{l}\text { Completely } \\
\text { improvement }\end{array}$ & - \\
\hline 11 & 64 & Male & $\mathrm{T} 11, \mathrm{~T} 12$ & $\begin{array}{l}\text { Pain+ } \\
\text { paraparesis }\end{array}$ & OLF & Laminoplasty & $\begin{array}{l}\text { Completely } \\
\text { improvement }\end{array}$ & - \\
\hline 12 & 66 & Male & $\mathrm{T} 11, \mathrm{~T} 12$ & Paraparesis & OLF & Laminoplasty & $\begin{array}{l}\text { Decrease of } \\
\text { paraparesis }\end{array}$ & - \\
\hline 13 & 68 & Female & $\begin{array}{l}\text { T4, T5, } \\
\text { T7, T8, } \\
\text { T9, T10, } \\
\text { T11, T12 }\end{array}$ & Paraparesis & $\mathrm{OLF}+\mathrm{DO}$ & Laminoplasty & $\begin{array}{l}\text { Decrease of } \\
\text { paraparesis }\end{array}$ & Dura defect \\
\hline 14 & 65 & Male & $\mathrm{T} 10, \mathrm{~T} 12$ & Paraparesis & OLF & $\begin{array}{l}\text { Posterior } \\
\text { instrumentation+ } \\
\text { total laminectomy }\end{array}$ & $\begin{array}{l}\text { Decrease of } \\
\text { paraparesis }\end{array}$ & - \\
\hline
\end{tabular}

T: thoracic, OLF: ossified ligamentum flavum, DO: dural ossification, pre-op: preoperative, post-op: postoperative

\section{Discussion}

Since the thoracic spine is relatively stable, myelopathy caused by pathologies developing in the thoracic spine is less common than myelopathy caused by pathologies developing in the cervical and lumbar spine (12). The diameter of the spinal canal is narrower in the thoracic region as compared to the other parts of the spinal canal. Therefore, any compression that occurs at this level causes severe neurological symptoms in patients (9). For this reason, when TSS is diagnosed, decompression surgery should be performed early in symptomatic cases. TSS may be caused by the OLF, ossification of the dura, herniation of the thoracic disc, and ossification of the posterior longitudinal ligament (2). Since TSS can often be associated with cervical and lumbar spinal canal diseases, its diagnosis and treatment may be delayed $(1,2)$. Of the patients with TSS and OLF included in this study, three had DO. In all cases, the entire spinal column was examined preoperatively using magnetic resonance imaging (MRI) and CT.

OLF is shown as the primary cause of thoracic myelopathy (13-16). The studies have reported that OLF is more common in the fifth and sixth decades of life, its incidence increases with age, and it is seen at a higher rate in East Asian countries, especially in Japanese people $(4,14,17-19)$. In many studies, factors such as genetics, dietary habits, mechanical stress, and cytokine production in the ligamentum flavum have been implicated in the etiology of OLF, and no definitive etiological factor has been reported (7). Histological studies have shown that fibroblastic proliferation contributes to endochondral ossification (20). It has been reported that thoracic OLF is most frequently seen at the lower thoracic spine at T10$\mathrm{T} 12$, followed by the upper thoracic spine at T1-T4, and rarely at T5-T9 $(21,22)$. This is due to the fact that because the mid-thoracic region is located posterior to the thoracic cage, and thus more stable, while the other regions are located in the cervicothoracic and 
thoracolumbar transition regions and are more exposed to mechanical stress (7). In the cases with OLF in this study, it was observed that the lower thoracic region was the most commonly affected region, and the middle thoracic region was rarely affected.

One of the other causes of thoracic myelopathy is DO, which can be seen in patients with OLF. In the literature, the incidence of DO has been reported to be ranging between $11 \%$ and $66.6 \%(19,23-25)$. CT is considered superior than to MRI in the diagnoses of DO. It has been reported that the etiology of DO is unclear and inflammatory reactions may be involved in its pathogenesis (17). In 2009, Muthukumar et al. defined two radiological signs for DO in preoperative CT imaging, tram trace sign and a comma sign (26). In this study, DO was detected in three cases (21.4\%).

In our clinical series, it was shown that severe DO did not manifest as a comma, or a tramway mark as described in the literature and that dural calcification expanded similar to the expansion of an intradural extramedullary mass and pushed the spinal cord (Figure 6).

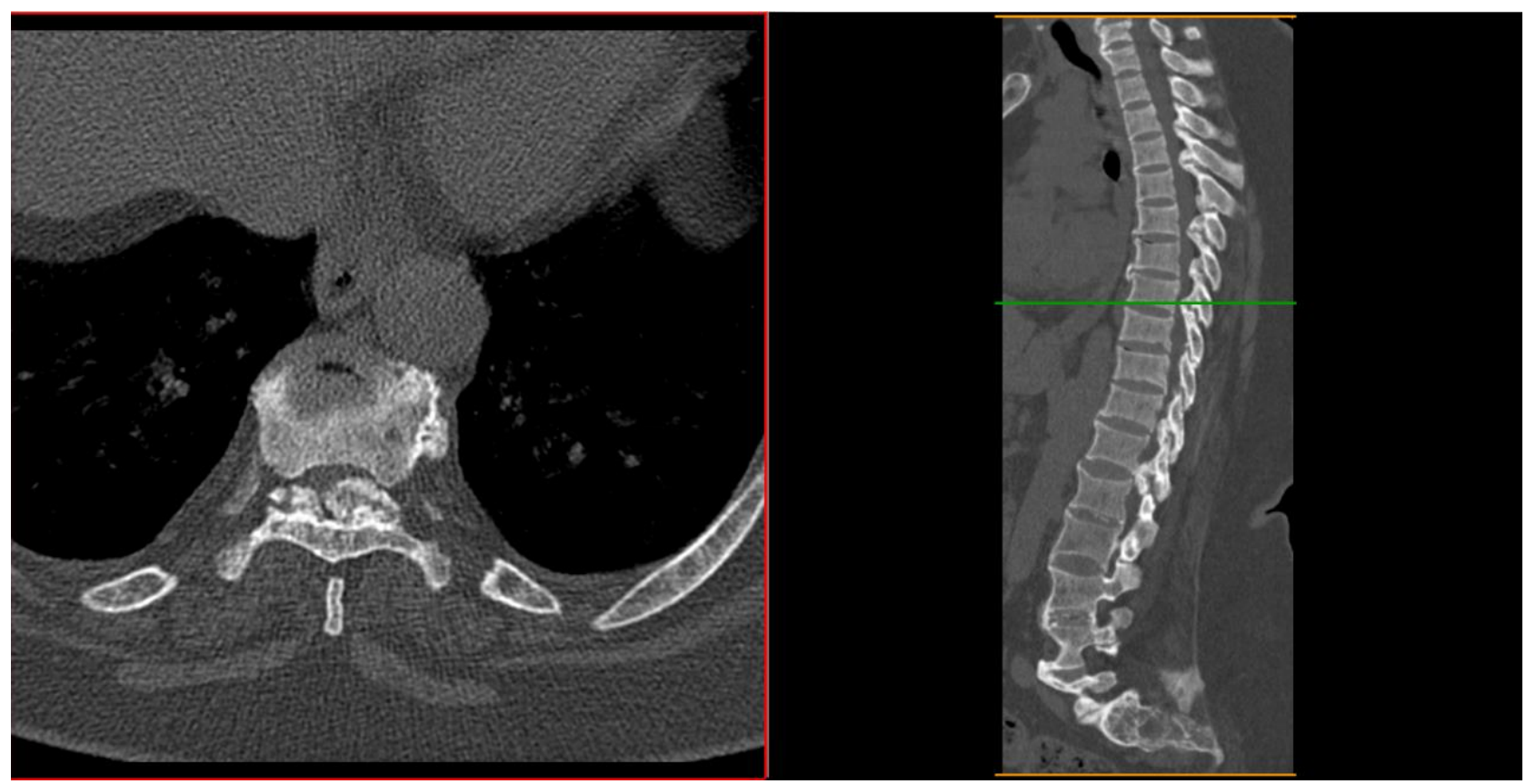

Figure 6. Intradural view of dural ossification

In one of our cases who presented to our clinic with symptoms of back pain, spasticity, and severe paraparesis had been diagnosed with XLH. In imaging studies, TSS was detected at multiple levels in the thoracic spinal canal (Figure 5, 6). XLH is the most common form of hereditary rickets and is characterized by renal phosphate loss. In affected patients, hyperplasia of fibrochondrocytes occurs in tendons and ligaments, causing thickening and ossification of the structures $(27,28)$. In the literature, there are a few reported cases with a diagnosis of $\mathrm{XLH}$, who developed stenosis due to calcification in the thoracic spinal canal causing myelopathy and/or paraplegia $(29,30)$.

The earliest symptom of TSS is an ataxic gait. As the stenosis worsens, spasticity and muscle atrophy occur, the patient experiences difficulties in standing balance and climbing stairs, numbness and hypoesthesia begin, and bladder and bowel disorders occur in the late stage $(7,11,17,25)$. The patients may rarely present with back pain. Conservative approaches have no place in the treatment of symptomatic cases $(17,31)$. Satisfactory outcomes can be achieved by adequate decompression with early treatment and employing appropriate surgical methods (18,32,33). Hemilaminectomy, total laminectomy, laminectomy with fusion and posterior instrumentation, and laminoplasty are the surgical techniques employed. In the literature, the addition of fusion to decompression surgery is controversial, and some studies argue that fusion should be added to prevent the development of early instability and kyphotic deformity $(11,20,26)$. In cases where the posterior longitudinal ligament is ossified, some authors consider that only decompression is appropriate $(11,20)$, while many authors have reported that laminectomy alone will not be sufficient, and fusion should be added $(34,35)$. In 
2019, Barath et al. reported that they performed decompression with fusion and instrumentation for the treatment of a patient with recurrent stenosis after undergoing posterior decompression (4). The addition of fusion to surgery is a more appropriate option, especially in pathologies in the thoracolumbar junction that have caused TSS. The facet joints can be adequately removed by both laminoplasty and laminectomy with fusion and posterior instrumentation, and thus the risk of re-stenosis can be minimized.

In spinal surgery applications, there are studies in which three-dimensional navigation systems are used instead of classical fluoroscopy (o-arm). There are studies Studies are showing that anatomic structure can be located precisely, and the placement of pedicle screws can be controlled more easily using these navigation systems $(36,37)$. In this study, classical fluoroscopy was used to determine the level, and two patients were re-operated after inadequate decompression was observed in control thoracic CT examination in the postoperative period.

In the literature, ultrasonic bone curettes have been shown to reduce cerebrospinal fluid (CSF) leakage in spinal surgeries, and the incidence of CSF leakage has been reported as $1.6 \%-9.8 \%(5,17,38)$. In this study, ultrasonic bone cutter and high-speed drills were used; by adjusting the cutting depth of the ultrasonic bone cutter, the laminae could be cut smoothly near the border of the bilateral facet joints and safely removed in an en-bloc manner. This technique was used in cases with only OLF without DO. In cases with DO, the DO was thinned with a high-speed drill until a thin layer remained and left as a thin lamella. Dural defect was observed in two patients, and duraplasty was performed using fascia graft in these cases. In one case, it was observed that the dural defect was caused by the bone cutter, and the other dural defect was caused by the intradural thickening.

Rehabilitation programs after surgery should be an integral part of the treatment in order to maximize independence in the mobilization of the patients and daily life activities, such as self-care and home-worksocial life management. The management of rehabilitation programs in patients with myelopathy due to ligamentum flavum pathology is very similar to the management of traumatic spinal cord injuries. The Conventional rehabilitation program should mainly consist of in-bed mobility of the patient, transfers, mobility with a wheelchair, sitting, sitting/standing, balance-coordination and walking exercises with or without an assistive device and retraining the patient about daily activities while considering the clinical condition of the patients in the postoperative period. In the postoperative period, prevention of complications, such as skin deterioration, deep venous thrombosis, and pulmonary embolism, pain management, spasticity, bowel, and bladder management should be handled appropriately $(39,40)$.

In this study, it was observed that the patients who were diagnosed in the early period and operated with adequate decompression before the onset of symptoms of severe myelopathy and who were included in the rehabilitation program in the early postoperative period, showed a significant and rapid clinical recovery.

\section{Conclusion}

It should be kept in mind that TSS causes slowly progressing thoracic myelopathy and minor traumas may accelerate the onset of symptoms. The outcomes of surgical treatment in the early period before the deterioration in clinical condition are satisfactory. In symptomatic cases, follow-up with conservative treatment is not appropriate. The authors consider that among the surgical methods employed, laminectomy with fusion and posterior instrumentation and laminoplasty will provide better decompression in these patients.

Ethics Committee Approval: The study was approved by the ethics committee of Kocaeli Derince Education and Research Hospital (project number 2020/42).

Peer-review: Externally peer-reviewed.

Author Contributions:

Concept: A.G; Design: A.G, M.S; Literature Search: A.G, M.S, T.G, Data Collection and Processing: A.G, M.S, T.G; Analysis or Interpretation: A.G, M.S, T.G; Writing: A.G, M.S, T.G.

Conflict of Interest: No conflict of interest was declared by the authors.

Financial Disclosure: The authors declared that this study hasn't received no financial support.

\section{References}

1. Palumbo MA, Hilibrand AS, Hart RA, Bohlman HH. Surgical Treatment of Thoracic Spinal Stenosis. Spine (Phila Pa 1976). 2001; 26(5): 55866.

2. Hou X, Sun C, Liu XY, Liu Z, Qi O, Guo Z, et al. Clinical Features of Thoracic Spinal Stenosisassociated Myelopathy; A Retrospective Analysis of 427 Cases. Clin Spine Surg. 2016; 29(2): 86-9. 
3. Li B, Qiu G, Guo S, Li W, Li Y, Peng H, et al. Dural ossification associated with ossification of ligamentum flavum in the thoracic spine: a retrospective analysis. BMJ Open. 2016; 6(12): e013887.

4. Barath AS, Wu OC, Patel M, Kasliwal MK. Repeated recurrence of thoracic spine stenosis following decompression alone for ossification of the ligamentum flavum: case report. J Neurosurg Spine. 2019; 30: 332-6.

5. Okada K, Oka S, Tohge K, Ono K, Yonenobu K, Hosoya T. Thoracic myelopathy caused by ossification of the ligamentum flavum. Clinicopathologic study and surgical treatment. Spine (Phila Pa 1976). 1991; 16: 280-7.

6. Yonenobu K, Ebara S, Fujiwara K, Yamashita K, Ono K, Yamamoto T, et al. Thoracic myelopathy secondary to ossification of the spinal ligament. J Neurosurg. 1987; 66: 511-8.

7. Yu S, Wu D, Li F, Hou T. Surgical results and prognostic factors for thoracic myelopathy caused by ossification of ligamentum flavum: posterior surgery by laminectomy. Acta Neurochir. 2013; 155: 1169-77.

8. Dützmann S, Fernandez R, Rosenthal D. Spinalkanalstenose im Thorakalbereich. Ätiologie, Pathogenese, Diagnostik und Therapie. Der Orthopäde. 2019; 48: 844-8.

9. Barnett GH, Hardy Jr RW, Little JR, Bay JW, Sypert GW. Thoracic spinal canal stenosis. J Neurosurg. 1987; 66: 338-44.

10. Epstein NE. Patients with "Lumbar Stenosis" and unrecognized distal thoracic cord compression. Spinal Surg. 2007; 21: 101-4.

11. Ahn DK, Lee S, Moon SH, Boo KH, Chang BK, Lee JI. Ossification of the ligamentum flavum. Asian Spine J. 2014; 8:89-96.

12. Amato V, Giannachi L, Irace C, Corona C. Thoracic spinal stenosis and myelopathy: report of two rare cases and review of the literature. J Neurosurg Sci. 2012; 56: 373-8.

13. Sun J, Zhang C, Ning G, Li Y, Li Y, Wang P, et al. Surgical strategies for ossified ligamentum flavum associated with dural ossification in thoracic spinal stenosis. J Clin Neurosci. 2014; 21: 2102-6.

14. Inamasu $\mathrm{J}$, Guiot $\mathrm{BH}$. A review of factors predictive of surgical outcome for ossification of the ligamentum flavum of the thoracic spine. $\mathrm{J}$ Neurosurg Spine. 2006; 5: 133-9.
15. Guo JJ, Luk KD, Karppinen J, Yang H, Cheung KM. Prevalence, distribution, and morphology of ossification of the ligamentum flavum: a population study of one thousand seven hundred thirty-six magnetic resonance imaging scans. Spine (Phila Pa 1976). 2010; 35: 51-6.

16. Yang Z, Xue Y, Zhang C, Dai Q, Zhou H. Surgical treatment of ossification of the ligamentum flavum associated with dural ossification in the thoracic spine. J Clin Neurosci. 2013; 20: 212-6.

17. Prasad GL. Thoracic spine ossified ligamentum flavum: single surgeon experience of fifteen cases and a new MRI finding for preoperative diagnosis of dural ossification. Br J Neurosurgery. 2020; 34(6): 638-46.

18. Shiokawa K, Hanakita J, Suwa H, Saiki M, Oda M, Kajiwara M. Clinical analysis and prognostic study of ossified ligamentum flavum of the thoracic spine. J Neurosurg 2001; 94: 221-6.

19. Miyakoshi N, Shimada Y, Suzuki T, Hongo M, Kasukawa Y, Okada K, et al. Factors related to long-term outcome after decompressive surgery for ossification of the ligamen- tum flavum of the thoracic spine. J Neurosurg. 2003; 99: 251-6.

20. Yayama T, Uchida K, Kobayashi S, Kokubo Y, Sato R, Nakajima H, et al. Thoracic ossification of the human ligamentum flavum:histopathological and immunohistochemical findings around the ossified lesion. J Neurosurg Spine. 2007; 7(2): 184-93.

21. Miyasaka K, Kaneda K, Ito T, Takei H, Sugimoto S, Tsuru N. Ossification of spinal ligaments causing thoracic radiculomyelopathy. Radiology. 1982; 143: 463-8.

22. Shiraishi T, Crock HV, Lewis P. Thoracic myelopathy due to isolated ossification of ligamentum flavum. J Bone Joint Surg Br. 1995; 77:131-3.

23. Ando K, Imagama S, Ito Z, Hirano K, Mramoto A, Kato F, et al. Predictive factors for a poor surgical outcome with thoracic ossification of the ligamentum flavum by multi- variate analysis. Spine (Phila Pa 1976). 2013; 38(12): 748-54.

24. Li F, Chen Q, Xu K. Surgical treatment of 40 patients with thoracic ossification of the ligamentum flavum. J Neurosurg Spine. 2006; 4: 191-7.

25. Aizawa T, Sato T, Sasaki H, Sasaki H, Kusakabe T, Morozumi N, Kokubun S. Thoracic myelopathy caused by ossification of the ligamentum flavum: clinical features and surgical results in the Japanese population. J Neurosurg Spine. 2006; 5(6): 514-9. 
26. Muthukumar N. Dural ossification in ossification of the ligamentum flavum: a preliminary report. Spine (Phila Pa 1976). 2009; 34 (24): 2654-61.

27. Gaucher C, Walrant-Debray O, Nguyen TM, Esterle L, Garabedian M, Jehan F. PHEX analysis in 118 pedigrees reveals new genetic clues in hypophosphatemic rickets. Hum Genet. 2009; 125(4): 401-11.

28. Liang G, Katz LD, Insogna KL, Carpenter TO, Macica CM. Survey of the enthesopathy of Xlinked hypophosphatemia and its characterization in Hyp mice. Calcif Tissue Int. 2009; 85: 235-46.

29. Ballantyne ES, Findlay GFG. Thoracic spinal stenosis in two brothers due to vitamin D-resistant rickets. Eur Spine J. 1996; 5(2): 125-7.

30. Riccio AR, Entezami P, Giuffrida A, Dowling J, Forrest G, German JW. Minimally Invasive Surgical Management of Thoracic Ossification of the Ligamentum Flavum Associated with $\mathrm{X}$ linked Hypophosphatemia. World Neurosurg. 2016; 94: 580.

31. Miyakoshi N, Shimada Y, Suzuki T, Hongo M, Kasukawa Y, Okada K, et al. Factors related to long-term outcome after decompressive surgery for ossification of the ligamentum flavum of the thoracic spine. J Neurosurg. 2003; 99(3): 251-6.

32. Liao CC, Chen TY, Jung SM, Chen LR. Surgical experience with symptomatic thoracic ossification of the ligamentum flavum. J Neurosurg Spine. 2005; 2(1): 34-9.

33. Mohindra S, Gupta R, Chhabra R, Gupta SK. Compressive myelopathy due to ossified yellow ligament among South Asians: analysis of surgical outcome. Acta Neurochir. 2011; 153 (3): 581-7.

34. Wang VY, Kanter AS, Mummaneni PV. Removal of ossified ligamentum flavum via a minimally invasive surgical approach. Neurosurg Focus. 2008; 25(2): 7.

35. Baba S, Oshima Y, Iwahori T, Takano Y, Inanami $\mathrm{H}$, Koga H. Microendoscopic posterior decompression for the treatment of thoracic myelopathy caused by ossification of the ligamentum flavum: a technical report. Eur Spine J. 2016; 25(6): 1912-9.

36. Wen BT, Chen ZQ, Sun CG, Jin KJ, Zhong J, Liu $\mathrm{X}$, et al. Three-dimensional navigation (O-arm) versus fluoroscopy in the treatment of thoracic spinal stenosis with ultrasonic bone cürette. Medicine (Baltimore). 2019; 98(20):e15647.
37. Luther N, Iorgulescu JB, Geannette C, Gebhard $\mathrm{H}$, Saleh T, Tsiouris AJ, et al. Comparison of navigated versus non-navigated pedicle screw placement in 260 patients and 1434 screws: screw accuracy, screw size, and the complexity of surgery. J Spinal Disord Tech. 2015; 28(5): 298303.

38. Kuh SU, Kim YS, Cho YE, Jin BH, Kim KS, Yoon YS, et al. Contributing factors affecting the prognosis surgical outcome for thoracic OLF. Eur Spine J. 2006;15(4): 485-91.

39. Ranee S, Thao D, Kerry B, Loretta G. Ossification of the Ligamentum Flavum Causing Thoracic Myelopathy. Am J Phys Med Rehabil. 1997; 76(1): 68-72.

40. Kubota S, Abe T, Kadone H, Shimizu Y, Funayama $\mathrm{T}$, Watanabe $\mathrm{H}$, et al. Hybrid assistive limb (HAL) treatment for patients with severe thoracic myelopathy due to ossification of the posterior longitudinal ligament (OPLL) in the postoperative acute/ subacute phase: A clinical trial. J Spinal Cord Med. 2019; 42(4): 517-25. 